Antônio Wesley Barbosa Pereira - luri Freires Viegas

Roberto de Sousa Junior - André da Costa Lima Michele Gonçalves Romcy Torres

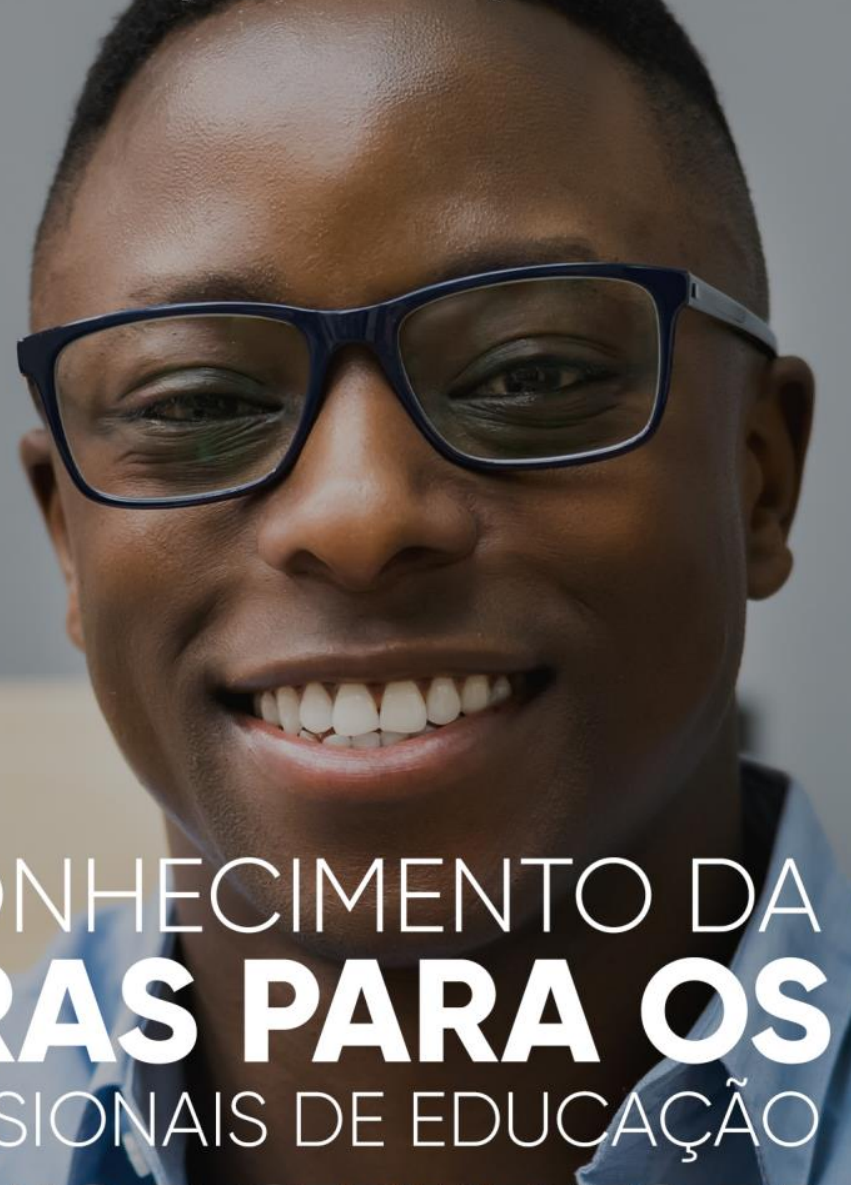

CONHECIMENTO DA DRAS PARA OS PROFISSIONAIS DE EDUCAÇÃO FISICA NO RECEBIMENTO DE ALUNOS SURDOS NAS ESCOLAS ESTADUAIS

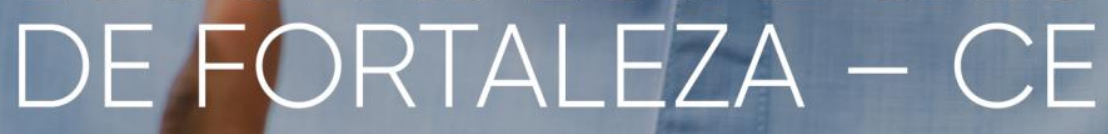

$1^{\circ}$ Edição

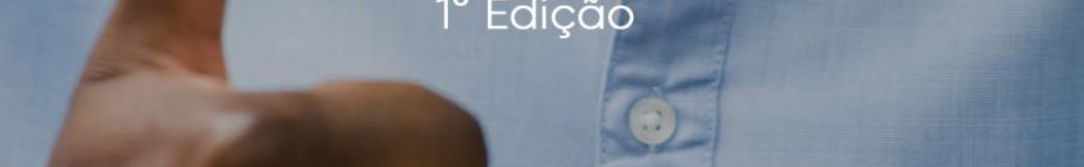

São José dos Pinhais

BRAZILIAN JOURNALS PUBLICAÇÕES DE PERIÓDICOS E EDITORA 
Antônio Wesley Barbosa Pereira - luri Freires Viegas

Roberto de Sousa Junior - André da Costa Lima

Michele Gonçalves Romcy Torres

\section{O conhecimento da libras para os profissionais de educação física no recebimento de alunos surdos nas escolas estaduais de Fortaleza - CE \\ $1^{\circ}$ Edição}




\author{
2021 by Brazilian Journals Editora \\ Copyright (C) Brazilian Journals Editora \\ Copyright do Texto (C2021 Os Autores \\ Copyright da Edição (C2021 Brazilian Journals Editora \\ Editora Executiva: Barbara Luzia Sartor Bonfim \\ Diagramação: Sabrina Binotti \\ Edição de Arte: Sabrina Binotti \\ Revisão: Os Autores
}

O conteúdo do livro e seus dados em sua forma, correção e confiabilidade são de responsabilidade exclusiva dos autores. Permitido o download da obra e o compartilhamento desde que sejam atribuídos créditos aos autores, mas sem a possibilidade de alterá-la de nenhuma forma ou utilizá-la para fins comerciais.

Conselho Editorial:

Profㄹ. Drª . Fátima Cibele Soares - Universidade Federal do Pampa, Brasil.

Prof. Dr. Gilson Silva Filho - Centro Universitário São Camilo, Brasil.

Prof. Msc. Júlio Nonato Silva Nascimento - Instituto Federal de Educação, Ciência e Tecnologia do Pará, Brasil.

Profa ${ }^{-}$Msc. Adriana Karin Goelzer Leining - Universidade Federal do Paraná, Brasil.

Prof. Msc. Ricardo Sérgio da Silva - Universidade Federal de Pernambuco, Brasil.

Prof. Esp. Haroldo Wilson da Silva - Universidade Estadual Paulista Júlio de Mesquita Filho, Brasil.

Prof. Dr. Orlando Silvestre Fragata - Universidade Fernando Pessoa, Portugal.

Prof. Dr. Orlando Ramos do Nascimento Júnior - Universidade Estadual de Alagoas, Brasil.

Profa - Dra . Angela Maria Pires Caniato - Universidade Estadual de Maringá, Brasil.

Profä. Drª. Genira Carneiro de Araujo - Universidade do Estado da Bahia, Brasil.

Prof. Dr. José Arilson de Souza - Universidade Federal de Rondônia, Brasil.

Profa . Msc. Maria Elena Nascimento de Lima - Universidade do Estado do Pará, Brasil.

Prof. Caio Henrique Ungarato Fiorese - Universidade Federal do Espírito Santo, Brasil.

Profạ. Drª. Silvana Saionara Gollo - Instituto Federal de Educação, Ciência e Tecnologia do Rio Grande do Sul, Brasil.

Profạ. Drª . Mariza Ferreira da Silva - Universidade Federal do Paraná, Brasil.

Prof. Msc. Daniel Molina Botache - Universidad del Tolima, Colômbia.

Prof. Dr. Armando Carlos de Pina Filho- Universidade Federal do Rio de Janeiro, Brasil.

Prof. Dr. Hudson do Vale de Oliveira- Instituto Federal de Educação, Ciência e Tecnologia de Roraima, Brasil.

Profa . Msc. Juliana Barbosa de Faria - Universidade Federal do Triângulo Mineiro, Brasil.

Profa ${ }^{-}$. Esp. Marília Emanuela Ferreira de Jesus - Universidade Federal da Bahia, Brasil.

Prof. Msc. Jadson Justi - Universidade Federal do Amazonas, Brasil. 
Profạ. Drª . Alexandra Ferronato Beatrici - Instituto Federal de Educação, Ciência e Tecnologia do Rio Grande do Sul, Brasil.

Profa ${ }^{-}$. Msc. Caroline Gomes Mâcedo - Universidade Federal do Pará, Brasil.

Prof. Dr. Dilson Henrique Ramos Evangelista - Universidade Federal do Sul e Sudeste do Pará, Brasil.

Prof. Dr. Edmilson Cesar Bortoletto - Universidade Estadual de Maringá, Brasil.

Prof. Msc. Raphael Magalhães Hoed - Instituto Federal do Norte de Minas Gerais, Brasil.

Profa ${ }^{a}$. Msc. Eulália Cristina Costa de Carvalho - Universidade Federal do Maranhão, Brasil.

Prof. Msc. Fabiano Roberto Santos de Lima - Centro Universitário Geraldo di Biase, Brasil.

Prof ${ }^{a}$. Dr ${ }^{a}$. Gabrielle de Souza Rocha - Universidade Federal Fluminense, Brasil.

Prof. Dr. Helder Antônio da Silva, Instituto Federal de Educação do Sudeste de Minas Gerais, Brasil.

Profa . Esp. Lida Graciela Valenzuela de Brull - Universidad Nacional de Pilar,

Paraguai.

Prof‥ Drª . Jane Marlei Boeira - Universidade Estadual do Rio Grande do Sul, Brasil.

Profa . Dra . Carolina de Castro Nadaf Leal - Universidade Estácio de Sá, Brasil.

Prof. Dr. Carlos Alberto Mendes Morais - Universidade do Vale do Rio do Sino, Brasil.

Prof. Dr. Richard Silva Martins - Instituto Federal de Educação, Ciência e

Tecnologia Sul Rio Grandense, Brasil.

Prof ${ }^{a}$. Dra ${ }^{\mathrm{a}}$. Ana Lídia Tonani Tolfo - Centro Universitário de Rio Preto, Brasil.

Prof. Dr. André Luís Ribeiro Lacerda - Universidade Federal de Mato Grosso, Brasil.

Prof. Dr. Wagner Corsino Enedino - Universidade Federal de Mato Grosso, Brasil.

Profa. Msc. Scheila Daiana Severo Hollveg - Universidade Franciscana, Brasil.

Prof. Dr. José Alberto Yemal - Universidade Paulista, Brasil.

Prof ${ }^{\mathrm{a}}$. Dr ${ }^{\mathrm{a}}$. Adriana Estela Sanjuan Montebello - Universidade Federal de São

Carlos, Brasil.

Profạ. Msc. Onofre Vargas Júnior - Instituto Federal de Educação, Ciência e Tecnologia Goiano, Brasil.

Profa ${ }^{-}$. Dr ${ }^{a}$. Rita de Cássia da Silva Oliveira - Universidade Estadual de Ponta Grossa, Brasil.

Prof ${ }^{a}$. Dra . Leticia Dias Lima Jedlicka - Universidade Federal do Sul e Sudeste do

Pará, Brasil.

Prof ${ }^{a}$. Dr ${ }^{a}$. Joseina Moutinho Tavares - Instituto Federal da Bahia, Brasil

Prof. Dr. Paulo Henrique de Miranda Montenegro - Universidade Federal da

Paraíba, Brasil.

Prof. Dr. Claudinei de Souza Guimarães - Universidade Federal do Rio de Janeiro, Brasil.

Prof ${ }^{\text {- }}$. Dr ${ }^{\mathrm{a}}$. Christiane Saraiva Ogrodowski - Universidade Federal do Rio Grande, Brasil.

Profa․ Drª . Celeide Pereira - Universidade Tecnológica Federal do Paraná, Brasil.

Profa ${ }^{a}$. Msc. Alexandra da Rocha Gomes - Centro Universitário Unifacvest, Brasil.

Profa ${ }^{\text {- Dra }}$. Djanavia Azevêdo da Luz - Universidade Federal do Maranhão, Brasil.

Prof. Dr. Eduardo Dória Silva - Universidade Federal de Pernambuco, Brasil.

Profa. Msc. Juliane de Almeida Lira - Faculdade de Itaituba, Brasil. 
Prof. Dr. Luiz Antonio Souza de Araujo - Universidade Federal Fluminense, Brasil. Prof. Dr. Rafael de Almeida Schiavon - Universidade Estadual de Maringá, Brasil. Profa . Dra . Rejane Marie Barbosa Davim - Universidade Federal do Rio Grande do Norte, Brasil.

Prof. Msc. Salvador Viana Gomes Junior - Universidade Potiguar, Brasil.

Prof. Dr. Caio Marcio Barros de Oliveira - Universidade Federal do Maranhão, Brasil.

Prof. Dr. Cleiseano Emanuel da Silva Paniagua - Instituto Federal de Educação, Ciência e Tecnologia de Goiás, Brasil.

Profa ${ }^{\text {. D }}$ Dra . Ercilia de Stefano - Universidade Federal Fluminense, Brasil. 


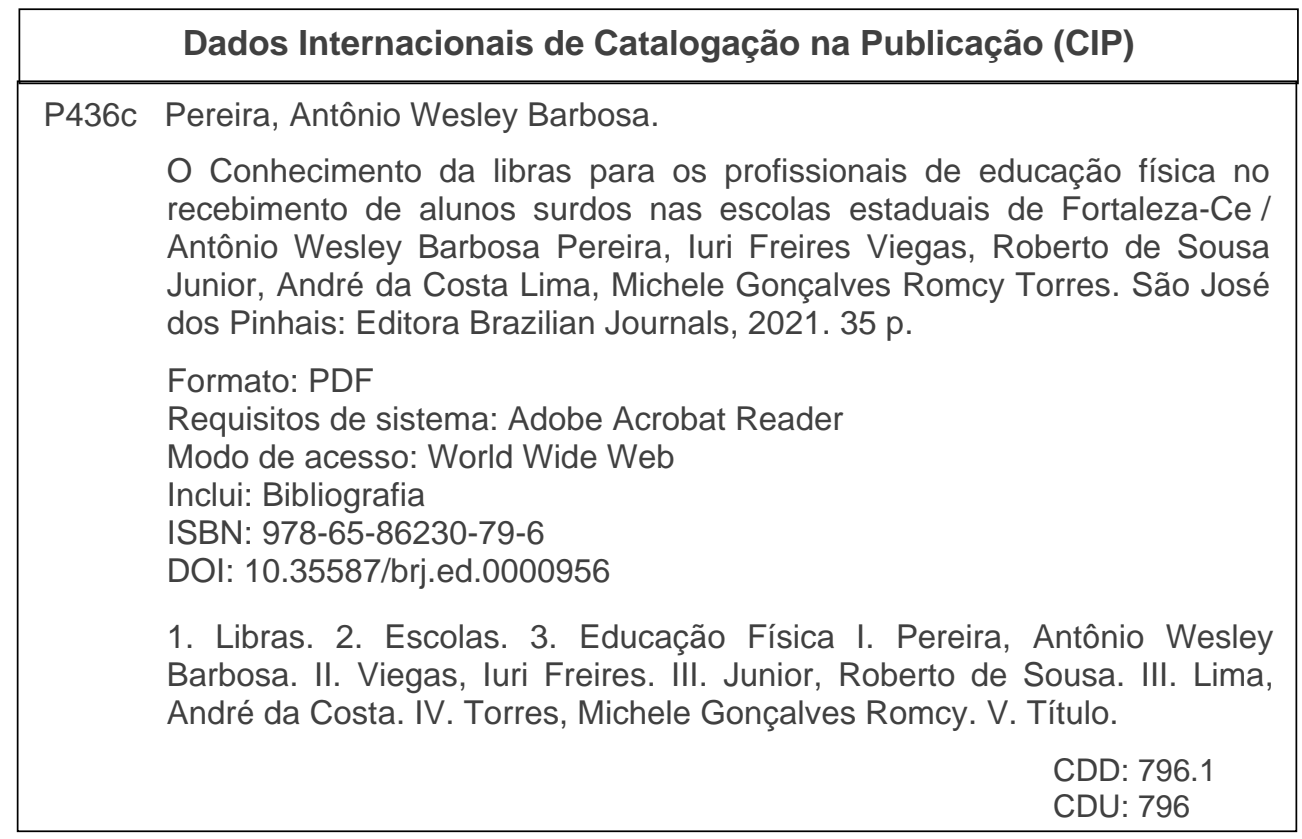

Ficha adaptada de Patrícia Maria de Lima Chaves CRB 3/828.

Brazilian Journals Editora

São José dos Pinhais - Paraná - Brasil

www.brazilianjournals.com.br editora@brazilianjournals.com.br 


\section{OS AUTORES}

\section{Antônio Wesley Barbosa Pereira}

Graduado em Bacharelado em Educação Física pela Faculdade de Piracanjuba

Faculdade de Piracanjuba - FAP de Goiás

Endereço: Av. Dr. Amym José Daher, Piracanjuba, QD 42 - GO, Brasil.

E-mail: antoniowesleybarbosapereira@gmail.com

\section{luri Freires Viegas}

Licenciatura em Educação Física- Universidade Federal do Ceará-UFC Endereço: Av. Mister Hull, s/n - Pici - CEP: 60455-760, Fortaleza - CE. E-mail: iuriviegas@gmail.com

\section{Roberto de Sousa Junior}

Educação física

Faculdade UNOPAR

Endereço: Rua lldefonso Albano 1030, Fortaleza - Ce.

E-mail: robertojunior373@gmail.com

\section{André da Costa Lima}

Centro Universitário Estácio do Ceará - Via Corpvs

Endereço: Rua Eliseu Uchôa Beco, 600, Patriolino Ribeiro - Fortaleza - CE, CEP: 60810-270.

E-mail: acl80@hotmail.com

\section{Michele Gonçalves Romcy Torres}

Doutora e Mestre em Educação Brasileira

Universidade Federal do Ceará

Endereço: Av. Mister Hull, s/n - Pici - CEP: 60455-760 - Fortaleza - CE.

E-mail:michelegrt@yahoo.com.br 
"Não me envergonho de mudar de ideia, porque não me envergonho de pensar".

(Freud) 
RESUMO: O profissional de educação física ao sair da graduação, deve estar preparado para o mercado de trabalho, pois vai trabalhar com todo tipo de aluno e está cada vez mais rotineiro receber educandos com surdez no ambiente escolar público ou privado. Esse estudo tem como objetivo verificar o conhecimento dos professores de educação física sobre o recebimento de educandos surdos nas escolas estaduais da cidade de Fortaleza - CE. Participaram da pesquisa 15 professores de educação física, distribuídas pelos 06 CREDES. A metodologia adotada para este estudo foi de campo com abordagem quantitativa e qualitativa, tendo o questionário de 16 perguntas como instrumento da pesquisa. Conclui-se que os professores de educação física participantes da pesquisa não possuem experiência com a educação física adaptada para alunos com surdez. Sendo por vários fatores: falta de procura dos mesmos para capacitação adequada, falta de experiência e proximidade de alunos com essa deficiência e o pensamento arcaico de que só é preciso demostrar os movimentos na aula prática de educação física, com uso de imagens e vídeos como o único instrumento pedagógico.

PALAVRAS-CHAVE: Educação Física Escolar. Libras. Surdez. 
ABSTRACT: The physical education professional when leaving college should be prepared for the job market, as he will work with all types of students and it is increasingly column to receive deaf students in the public or private school system. This study aims to verify the knowledge of physical education teachers about the reception of deaf students in the state schools of the city of Fortaleza - CE. Fifteen physical education teachers participated in the study, distributed throughout the 06 CREDES. The methodology adopted for this study was field with a quantitative and qualitative approach, having a questionnaire with 16 questions as a research tool. It is concluded that the physical education teachers participating in the research do not have experience with physical education adapted to deaf students. Due to several factors: lack of pursuing adequate training, lack of experience and closeness of students with this deficiency, and the archaic thinking that it is only necessary to demonstrate the movements in the practical class of physical education, using images and videos as the only pedagogical instrument.

KEYWORDS: School Physical Education; Libras; Deafness. 
SUMÁRIO

1. INTRODUÇÃO

2. METODOLOGIA

3. RESULTADOS

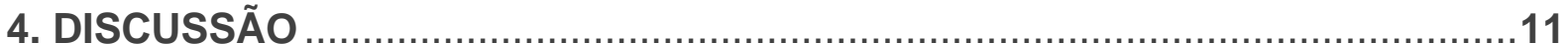

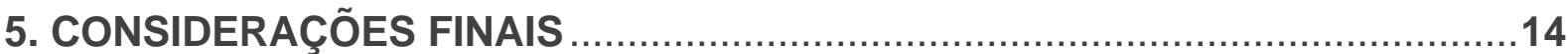

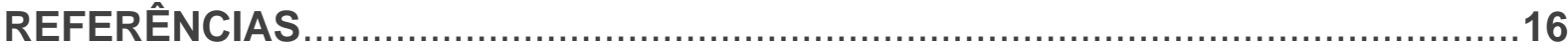

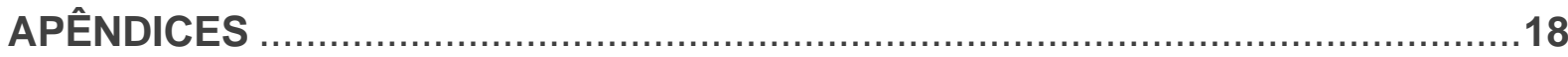




\section{INTRODUÇÃO}

Os surdos utilizam de gestos organizados e sistematizados para se comunicarem. Relata Mendes, Figueredo e Ribeiro (2016) que inicialmente chamado de linguagem gestual em meados do século XVI se dá pela criação do alfabeto manual por Chaeles Michel L' Epée. IACHINSKI et al., (2019) Salienta que a disciplina de LIBRAS nas licenciaturas desmistifica conceitos equivocados sobre a surdez, prática pedagógica mais eficaz que beneficie esse público e difusão da língua de sinais neste ambiente

Para que os surdos pudessem utilizar dessa linguagem no cotidiano e ambientes escolares tiveram que passar por vários procedimentos médicos e educacionais sofredores, até conseguir o direito da sociedade brasileira se adequar a deficiência, ou seja, mudanças nos procedimentos da educação e da saúde para acomodar melhor as particularidades da deficiência.

Depois da lei $\mathrm{n}^{\circ} 10.436$ (BRASIL, 2002), regulamentada pelo decreto 5.626 de dezembro de 2005 (BRASIL, 2005) no qual o Art. 2ํ diz que o poder público garante o apoio das empresas concessionárias que atendem o público de forma geral, como meio de comunicação da comunidade surda. Deste então, essas pessoas ganharam mais notoriedade na sociedade, nesse sentindo, a Libras se tornou disciplina obrigatória na grade curricular dos cursos de licenciatura em geral e fonoaudiologia na área da saúde.

O profissional ao sair da graduação, deve estar preparado para o mercado de trabalho, pois, vai trabalhar com todo tipo de alunos. Está cada vez mais rotineiro receber surdos no ambiente escolar público ou privado, segundo o Instituto Brasileiro de Geografia e Estatística (IBGE, 2010) 46,6\% das pessoas que se declaram deficientes ganham no máximo um salário mínimo, diferente de 37,1 das pessoas sem qualquer deficiência. A mesma pesquisa revela que a maioria das pessoas com deficiência está concentrada em níveis de instrução e de rendimento muito baixos.

Nas escolas e também em nível superior é importante que os professores saibam pelo menos um pouco da Libras, ou que a escola disponibilize intérpretes para Ihes auxiliar na diminuição do desperdício de tempo dos alunos surdos, que podem não compreender as informações do conteúdo que o professor está 
transmitindo. Segundo Nunes et al., (2015) os professores priorizam a oralização do aluno ou a leitura labial na hora de transmitir o conteúdo do que propriamente a utilização da Libras.

Infelizmente, os professores brasileiros não se sentem totalmente preparados para atender esse público, segundo PACHECO; ALVES; DUARTE (2017) afirmam que estudos realizados na área apontam falhas na formação inicial, que ainda não é capaz de fornecer os conhecimentos necessários a mudança da pratica pedagógica do professor de Educação Física, pois não têm uma vinculação prática com o contexto de atuação profissional.

Em meados do século XIX a aula de educação física era tida como a hora de se exercitar na escola, (RODRIGUES, 2017) afirma que a escola que tem profissionais de Educação Física deve enumerar os estímulos desenvolvidos em suas aulas como: percepção corporal, noções de espaço-tempo, sensibilidade ao tato, visão, audição, além de valências físicas. Através disso é que existe a necessidade das escolas lutarem pela inclusão.

Nas aulas de educação física não se aprende apenas o conteúdo da matéria engessado e limitado, mas também tem a principal função de abranger os seguimentos educacionais levando o aluno a construir e desenvolver a consciência crítica, ética e moral como preparação para o mercado de trabalho, conscientização para preservação da saúde e formação cidadã. PACHECO; ALVES; DUARTE (2017) relatam que o professor deve ter uma formação sólida, pautada sobre os valores da educação inclusiva e com base nos problemas encontrados no seu futuro contexto de prática profissional.

Os Parâmetros Curriculares Nacionais (PCNs) documento oficial do Ministério da Educação dispõe de três blocos de conteúdos, porém, o enfoque maior são os temas transversais que possibilitam a construção da cidadania e compreensão da realidade. Os PCNs (1997) discorrem que as disciplinas convencionais na grade curricular do ensino fundamental não são suficientes para abordarem temas da realidade social, como saúde, violência, mercado de trabalho entre outros.

O método bilíngue de aprendizagem para os surdos já é apontado como o melhor método a ser utilizado nas escolas, ou seja, o aluno aprende Libras paralelamente com o português escrito. Santos, Coelho e Klein (2016) discorrem que no Brasil a legislação já considera o bilinguismo para educação de surdos. E em 
especial na cidade de Fortaleza existem escolas inclusivas e uma bilíngue para o público surdo.

Segundo a LDB (Lei de Diretrizes e Bases da Educação Nacional) Lei 9.394/96 especialmente nó capítulo II seção IV art.35 "no ensino médio as escolas são responsáveis a aprofundar o conhecimento adquirido no ensino fundamental e preparar o jovem para o mercado de trabalho e cidadania". Uma das dificuldades dos professores é quando o aluno surdo é incluído na sala de aula com escolares ouvintes, é preciso atender as particularidades dele como pessoa, já que o mesmo deve aprender duas línguas: a Libras e o Português escrito.

Segundo UCHÔA; NICOLETTI; CARDOSO (2012) o processo de Inclusão de alunos com deficiência é um processo amplo e árduo. Exige uma série de transformações do ambiente escolar, afim de possibilitar o pleno desenvolvimento de seus alunos. Mesmo existindo lei e decreto que assegura a Libras no ambiente escolar e a obrigatoriedade das escolas receberem educandos surdos, a inclusão na sala de aula ainda é questionável sobre diversas formas de abordagens sendo elas produtivas ou não pelos professores.

O estudo além de contribuir socialmente para discussões de problemáticas que rodeiam a educação dos sujeitos surdos o objetivo é verificar o conhecimento dos professores de educação física sobre o recebimento de educandos surdos nas escolas estaduais da cidade de Fortaleza - CE. 


\section{METODOLOGIA}

\subsection{Planejamento da pesquisa}

Foi realizada uma pesquisa de campo com abordagem mista: quantitativa e qualitativa, no período entre agosto e outubro de 2016. A autorização foi pelo Termo de Consentimento Livre e Esclarecido (TCLE - Apêndice 1), para os professores das instituições que foram visitadas e a carta de anuência (Apêndice 2) para a autorização das escolas para a pesquisa.

\subsection{Local de estudo}

A cidade de Fortaleza - CE está dividida pelo governo do estado do Ceará em 06 regiões pela Coordenadoria Regional de Desenvolvimento da Educação (CREDE). Foram visitadas 2 instituições de cada CREDE totalizando 12 escolas regulares de nível médio distribuídas por essas regiões. As escolas foram escolhidas de forma aleatória através de sorteio.

\subsection{Amostra}

A amostra foi composta por 15 professores de educação física das escolas públicas regulares no nível médio, distribuídas pelas 06 CREDEs.

\subsection{Instrumentos e procedimentos}

Foi utilizada a listagem das escolas estaduais de Fortaleza - CE disponível no site do governo do estado do Ceará, para o sorteio das 12 escolas sendo duas de cada CREDE. Foi desenvolvido um questionário semiestruturado (Apêndice 3) pela carência de instrumentos que contribuiriam com o trabalho.

O mesmo está organizado em duas partes, sendo elas: a primeira abordando as variáveis da pesquisa como sexo, idade, escola, região, tempo de magistério e nível máximo de formação. E a segunda parte composta por 16 perguntas distribuídas sobre análise de currículo, experiências de vida, instrumentos e técnicas pedagógicas utilizadas na rotina estudantil e sugestões para melhorar o atendimento do aluno surdo.

Depois de agendar e solicitar as autorizações das direções das escolas foi aplicado o questionário para os professores dentro da instituição escolar antes ou 
depois das aulas de educação física ou ainda no planejamento pedagógico dependendo da disponibilidade dos mesmos para responder à pesquisa.

\subsection{Tratamento dos dados}

Para a organização dos dados foram utilizados o Microsoft Office Excel e o programa Statistical Package for the Social Sciences (SPSS) for Windows versão 20.0 SPSS para a tabulação dos resultados. A apresentação dos dados no presente trabalho está por meio de tabelas para as perguntas objetivas e os relatos pessoais dos professores foram transcritos a partir das perguntas subjetivas. 


\section{RESULTADOS}

De acordo com os dados obtidos pelo questionário distribuídos aos professores, as respostas das perguntas objetivas foram organizadas nas tabelas abaixo:

Tabela 1: Caracterização dos participantes conforme o perfil traçado dos professores nas escolas estaduais de Fortaleza - CE, 2016.

\begin{tabular}{|c|c|c|c|c|c|}
\hline Professor (a) & Sexo & Idade & Região & $\begin{array}{c}\text { Tempo de } \\
\text { magistério }\end{array}$ & $\begin{array}{c}\text { Nível máximo } \\
\text { de formação }\end{array}$ \\
\cline { 1 - 4 }$(\mathbf{P})$ & $\mathrm{M}$ & 32 & CREDE 01 & 4 & Mestrado \\
\cline { 1 - 4 } & $\mathrm{M}$ & 33 & CREDE 01 & - & Graduação \\
\hline 2 & $\mathrm{M}$ & 45 & CREDE 01 & 19 & Especialização \\
\hline 3 & $\mathrm{M}$ & 49 & CREDE 02 & 32 & Especialização \\
\hline 4 & $\mathrm{~F}$ & 42 & CREDE 02 & 16 & Especialização \\
\hline 5 & $\mathrm{M}$ & 33 & CREDE 03 & 11 & Especialização \\
\hline 6 & $\mathrm{~F}$ & 28 & CREDE 03 & 2 & Graduação \\
\hline 7 & $\mathrm{M}$ & 54 & CREDE 04 & 28 & Especialização \\
\hline 8 & $\mathrm{M}$ & 34 & CREDE 04 & 7 & Especialização \\
\hline 9 & $\mathrm{M}$ & 53 & CREDE 04 & 31 & Especialização \\
\hline 10 & $\mathrm{~F}$ & 49 & CREDE 06 & 30 & Especialização \\
\hline 11 & $\mathrm{~F}$ & 49 & CREDE 06 & 30 & Especialização \\
\hline 12 & $\mathrm{M}$ & 23 & CREDE 06 & 2 & Graduação \\
\hline 13 & $\mathrm{M}$ & 25 & CREDE 06 & 5 & Especialização \\
\hline 14 & $\mathrm{M}$ & 58 & CREDE 05 & 24 & Especialização \\
\hline 15 & & & & \\
\hline
\end{tabular}

Fonte: Os autores.

A tabela 1 mostra que a maioria dos professores é do sexo masculino com idade média de 40 anos, distribuídos pelos seis CREDES da cidade de Fortaleza, Ceará. O tempo médio de magistérios dos participantes da pesquisa é de 17 anos, com nível máximo de formação: três graduados, onze especializados em diferentes áreas e apenas um com mestrado.

A tabelas abaixo dispões das respostas dos professores sobre perguntas específicas da rotina trabalho e o seu currículo profissional, como também suas frustrações e sugestões sobre os recebimentos de alunos surdos nas escolas regulares onde eles atuam. 
Tabela 2: Apresentação das respostas dos professores às perguntas objetivas do questionário.

\begin{tabular}{|c|c|c|c|}
\hline Pergunta & Sim & Não & Total \\
\hline 1. Possui formação para alunos com deficiência? & 6 & 9 & 15 \\
\hline $\begin{array}{l}\text { 2. Você possui ou\ já possuiu algum aluno (a) com surdez } \\
\text { (com deficiência auditiva / surdos)? }\end{array}$ & 6 & 9 & 15 \\
\hline 3. Você considera importante o professor saber Libras? & 14 & 1 & 15 \\
\hline 4. Você teve disciplina de Libras na graduação? & 4 & 11 & 15 \\
\hline 5. Você sabe Libras? & 1 & 4 & 5 \\
\hline $\begin{array}{c}\text { 6. Você sente a necessidade de se capacitar nas áreas de } \\
\text { educação física adaptada e inclusiva? }\end{array}$ & 4 & 11 & 15 \\
\hline $\begin{array}{l}\text { 7. Sua carga horária de trabalho permite que você continue } \\
\text { se capacitando profissionalmente? }\end{array}$ & 13 & 2 & 15 \\
\hline $\begin{array}{l}\text { 8. Em sua opinião, as políticas de inclusão estão sendo } \\
\text { suficiente para a capacitação dos professores para o público } \\
\text { de alunos com surdez? }\end{array}$ & 7 & 8 & 15 \\
\hline $\begin{array}{l}\text { 9. A avaliação da aprendizagem foi diferenciada para os } \\
\text { alunos com surdez? }\end{array}$ & 2 & 12 & 14 \\
\hline $\begin{array}{l}\text { 10. Você teve dificuldade para avaliar esse público } \\
\text { diferenciado? }\end{array}$ & 2 & 8 & 10 \\
\hline $\begin{array}{l}\text { 11. Você faria algum curso para facilitar a sua atuação com } \\
\text { esse público específico? }\end{array}$ & 3 & 7 & 10 \\
\hline
\end{tabular}

Fonte: Os autores.

A tabela 2 mostra as respostas dos professores voltadas ao recebimento de educandos surdos em escolas regulares de nível médio de acordo com suas experiências. Abaixo está o complemento das respostas escritas de cada pergunta.

Sobre a formação na área de deficiência 9 não tiveram formação e 6 relataram que possuíam a capacitação em congressos sobre o assunto (P1) [sic], como voluntário de programas de pessoas com incapacidades (P4) [sic], mini cursos e oficinas (P7)[sic], Especialização em educação especial (P12) [sic], curso de Libras, mas incompleto (P13) [sic] e na Associação de Pais e Amigos dos Excepcionais (APAE).

Apenas 6 tiveram experiência com alunos surdos em sala de aula e 9 não tiveram nenhum contato com esses alunos. Na pergunta seguinte 14 dos professores responderam que considera importante o uso da Libras para os profissionais nas escolas e apenas 1 desconsidera essa importância. Porém a realidade dos mesmos é que 11 não tiveram a disciplina na grade curricular da graduação e 4 já estava incluída como forma obrigatória do curso. 
Dos quinze professores, 4 professores sabem Libras, 1 afirmou que sabe de forma superficial e básica, 11 não sentem necessidade de se capacitarem na área da educação física inclusiva, diferentemente de 4 que consideram importante essa formação. Quando questionados sobre a relação de carga horária e tempo para se capacitarem, 13 responderam que existe sim a interferência uma na outra e que possui tempo para se capacitar e 2 relataram falta de tempo.

A partir das respostas dos professores sobre cursos de capacitação oferecidas pelas políticas públicas na área da educação física inclusiva, 7 professores relatam que há ofertas de cursos por parte do governo e 8 responderam que não existe esse apoio. A qualidade do ensino está diretamente relacionada com a forma que o professor vai ensinar e cobrar do aluno na rotina escolar.

No que diz respeito às particularidades da avaliação dos alunos surdos, 2 professores diferenciaram a forma de avaliar esse aluno e 12 responderam que não foi diferenciado. 10 não tiveram dificuldades em avaliar, e 2 afirmaram que sentiram dificuldades na avalição, pois relataram que [...] não tem nenhum conhecimento da linguagem dos surdos [sic] (P.05) e nas provas escritas, as alunas confundiam algumas letras. Os demais relataram que não sentiram dificuldades, o que leva a pensar que, a avaliação pode ter sido superficial ou displicente, já que apernas um professor respondeu que sabia a Libras na pergunta um.

Quando perguntados sobre a vontade de fazer cursos de capacitação na área de Libras, apenas 3 sentiam essa necessidade, 7 não tem vontade e 5 não responderam.

Nas perguntas subjetivas do questionário os professores enriquecem mais o trabalho detalhando as suas experiências relacionadas aos educandos surdos na escola, expondo suas dificuldades e as ferramentas pedagógicas utilizadas para a diminuição das dificuldades dos professores passarem o conteúdo teórico.

Sobre como reagiram ao se deparar com o aluno surdo em sua turma, os professores que já passaram por essa experiência responderam: Normalmente [sic] (P1), [...] procurei um curso para informações adicionais [sic] (P2) [...] assusta, mas o auxílio de intérprete facilita o trabalho (quando ela estava presente) [sic] (P7), Ela possuía interprete e corria tudo muito bem [sic] (P8), Tive dificuldade de comunicação e precisei da ajuda de outra pessoa, inclusive a mãe da aluna [sic] (P11), com naturalidade. O aluno lia lábios (oralizado) e usava aparelho. Pouca dificuldade de comunicação. [sic] (P12). 
Quando questionados se por acaso tivessem ou tem alunos surdos em sua turma, que tipo de recursos alternativos eles utilizariam para otimizar a compreensão desses alunos nas aulas, 3 não responderam e 12 relataram da seguinte forma: Uso de recursos visuais (P1, P2, P4, P7, P8, P9, P10, P13), da Libras (P1 e P2), exemplos práticos visuais em aulas práticas (P1), caso o aluno saiba leitura labial poderia ser utilizado como ferramenta (P2), por "gestos" (P5), pela escrita e textos (P5, P8, P9 e P13), uso de interpretes (P6, P11, e P12) e aplicativos de celulares [sic] (P7).

Quanto as dificuldades ao receberem alunos surdos nas aulas, os professores relatam que falta conhecimento da Libras e a comunicação (P2, P5, P7, P11 e P12), única dificuldade é quando o intérprete falta [sic] (P8), como avaliar o aluno para que o mesmo não seja prejudicado no seu aprendizado [sic] (P10) e acessibilidade da escola [sic] (P13). já os P6, P14 e P15 não se pronunciaram em relação ao possível recebimento desses alunos.

No que diz respeito às dificuldades encontradas para a efetivação da inclusão do aluno surdo na escola, segundo os professores, começa na aceitação da comunidade escolar [sic] (P1), falta de capacitação e de incentivo; frequentemente as instituições especializadas são desligadas, não favorecendo a inclusão de alunos surdos em turmas regulares (P2, P3, P8 e P11), acho que a forma de comunicação, e o preconceito também com os demais colegas. Também pela própria dificuldade de lecionar para as pessoas especiais [sic] (P5), A própria sociedade e escolas devem ser melhores conscientizadas para que estas pessoas sintam-se mais acolhidas e consequentemente desenvolva o seu potencial. Menos preconceito e mais suporte [sic] (P9), Principalmente Políticas de Inclusão; Maior interesse dos órgãos competentes [sic] (P10) e na preparação de corpo docente da escola e funcionários para receber alunos com surdez [sic] (P12).

As sugestões que os professores deram para que exista uma melhor inclusão dos alunos com surdez, são: Um maior trabalho das gestões das escolas sobre 0 tratamento das pessoas D.A (Deficiente Auditivo) uma maior atenção da secretaria de educação para capacitação nessa área. O professor precisa ir atrás de se capacitar e atuar com qualidade nessa área para oferecer ensino de qualidade [sic] (P1), maior convivência (interação) com os círculos - apesar de a comunicação ser dificultada por desconhecimento de Libras, outras linguagens (escrita) e o conhecimento quotidiano dos surdos e das suas relações; favoreceriam aceitação e 
conhecimento desses alunos surdos com os demais indivíduos e vice-versa [sic] (P2), Uma capacitação ofertada para os professores da rede pública (P3, P4, P5, $\mathrm{P} 6, \mathrm{P} 9, \mathrm{P} 13)$, ensino obrigatório de libras no ensino básico e superior, em caso de licenciatura (P7 e P8), Trazer um interprete para auxiliar o aluno durante as aulas e fazer o feedback entre o professor e aluno [sic] (P11) e a linguagem de sinais deveria ser mais difundida no país, políticas públicas nesse direcionamento [sic] (P14). 


\section{DISCUSSÃO}

Dos professores participantes da pesquisa 9 se sentem inseguros no recebimento de alunos surdos e 6 possui algum tipo de capacitação. Em relação a um estudo feito sobre análise da inclusão do aluno surdo nas aulas de Educação Física regular na perspectiva dos professores de uma Escola Estadual, na cidade de Caratinga, Silva e Porto (2016) relatam que os dois professores que atendem alunos surdos na escola regular possuem experiência com educação inclusiva através do cotidiano.

Quatorze professores entendem que é importante saberem Libras e 1 não concorda com essa opinião, o estudo que aborda o assunto "A inclusão que exclui: a realidade dos alunos surdos da rede regular de ensino", a professora observada durante 12 aulas com aluno surdo e intérprete, Silva et al., (2016) detectaram o despreparo da professora lecionando para o educando. Segundo Santos, Coelho e Klein (2016) o decreto 5.626/2005 não declara qual a formação que os professores de escolas precisam ter.

Nesse estudo 4 professores tiveram disciplina de Libras na graduação enquanto 11 não tiveram. Silva e Porto (2016) identificaram que os conhecimentos práticos pedagógicos dos professores só serão ampliados quando os mesmos estiverem atuando no dia a dia do espaço escolar. Decreto 5.626/2005 art. 13. (BRASIL, 2005) discorre que o português escrito como segunda língua para os surdos deve ser inclusa como disciplina para formação dos alunos em nível infantil, fundamental, médio e superior.

Sobre o entendimento da LIBRAS pelos professores nesta pesquisa 1 sabe Libras, 4 não sabem e 10 não respondem, o que não se torna diferente de IACHINSKI et al., (2019) mostram em seu estudo que 25 (Vinte e cinco) participantes, ou seja, $42,37 \%$, responderam que tiveram contato com algum surdo antes de entrar para a universidade. Dentre estes, 11 responderam que estudaram com alguém surdo; 3 , que trabalharam com um surdo; 2 , que possuíam familiares surdos e 9 participantes tiveram suas respostas agrupadas na categoria "outros", por considerarem que já haviam tido contato com um surdo, pelo fato de já terem visto um.

Porto e Silva (2016) afirmaram que dos dois professores pesquisados nenhum possuem curso de Libras. Segundo Silva et al., (2016) todos os 14 
professores pesquisados desconhecem a Libras. A presença do intérprete nas escolas estaduais ainda é difícil, não por incompetência da escola, mas porque a demanda desse profissional ainda é escassa (POTILHO et al., 2021), o que faz ser mais demorada a educação e a inclusão dos surdos no meio educacional e social.

Quando questionado se sentem necessidade de se capacitarem na área da Libras, 4 sentem essa necessidade e 11 desconsidera essa importância. Um estudo sobre a atuação dos intérpretes de Libras com educandos surdos no ensino fundamental Junior e Zancanaro (2016) os dois professores participantes da pesquisa entendem pouco da Libras.

Quando questionados se a disciplina de Libras na graduação foi suficiente para se sentirem seguro em receber educandos surdos na sala, 4 responderam que sim e 11 afirmaram que não. Nascimento e Sofiato (2016) constataram que o problema da disciplina de Libras na graduação é a carga horária incabível para o aprendizado da Língua e aprofundamento do conteúdo.

Quando perguntados se são ofertados pelas políticas públicas capacitações na área de educação física inclusiva há quase um empate 7 responderam que sim e 8 não. Mesmo os professores afirmando que não há políticas públicas, a cidade de Fortaleza disponibiliza cursos gratuitos na área da educação adaptada. No entanto, a formação inicial do professor de Educação Física ainda é um obstáculo à inclusão nas aulas de Educação Física (PACHECO; ALVES; DUARTE, 2017)

As avalições dos professores desse estudo 2 disseram que foi diferenciada e 12 afirmaram que foram avaliados da mesma forma que os demais alunos. Anache e Resende (2016) relatam que os professores participantes do estudo demonstraramse insatisfeitos com a forma como avaliam seus alunos com deficiência intelectual, expondo inquietações sobre a prática instituída. Mesmo com o estudo de deficiências diferentes a dificuldade encontrada na rotina escolar também é de grande relevância para entendermos as dúvidas e frustações dos mesmos na hora de avaliar.

Quando questionados se tiveram alguma dificuldade na hora de avaliar o educando surdo 2 responderam que sim e 12 não tiveram. Segundo Almeida (2012, p. 34): "é evidente que a principal dificuldade quando se trata de educação inclusiva é a formação do professor, e repetidas vezes é mencionada a falta de preparo desse profissional". 
Dos participantes da pesquisa 6 professores tem alguma vivência com os alunos surdos e das respostas analisadas um único professor não teve dificuldades em lecionar para o educado surdo, justamente por saber Libras, de acordo com as respostas nos leva a pensar que, se não for por meios externos como por exemplo, o aluno saber a leitura labial, o uso do interprete ou até mesmo um membro da família auxiliando o professor na sala da aula, o professor se torna incapaz de atender alunos surdos na sua turma.

Pensando de forma hipotética, pode-se supor que o professor de Educação Física deve buscar por diferentes estratégias de ensino, logo, estimular a participação do aluno, a fim de avaliar a interação que o estudante estipula seu grau de motivação nas atividades, seu estágio de concentração, determinação, esforço e persistência, além das suas reações a vitórias e perdas (PIMENTA et al., 2019).

Uma ferramenta bastante utilizada é o intérprete, que para trabalhar em escolas Santos, Coelho e Klein (2016) afirmam que "o tradutor/ intérprete de Libras deve ter formação em curso superior de Tradução e Interpretação, com habilitação em Libras/Língua Portuguesa". Um estudo realizado por Portilho et al., (2021) sobre a formação docente do professor surdo: aproximações e distanciamentos com a identidade docente relatam que os (as) alunos(as) surdos (as), quando perguntados (as) sobre como se sentiam estudando com os (as) ouvintes, quase a totalidade deles (as) afirmou que tal situação exige muito sacrifício, paciência e esforço.

Mesmo com essa realidade, a avaliação com os educandos é de extrema importância para identificar as dificuldades do aluno, saber se absorção do conteúdo está acontecendo de fato, observar o desenvolvimento durante o período letivo e apresentar os pontos no que o professor deve melhorar ou não na didática do ensino. Para estes alunos a avaliação deve ser diferenciada de acordo com suas deficiências, pois há diferenças culturais, sociais e também de linguagem. 


\section{CONSIDERAÇÕES FINAIS}

Os professores de educação física da pesquisa não possuem experiência com a educação física adaptada para alunos com surdez. Sendo por vários fatores: o desinteresse dos mesmos na capacitação adequada, falta de experiência e proximidade dos alunos surdos e o pensamento antigo de que só é preciso apenas demostrar os movimentos na aula prática de educação física, com uso de imagens e vídeos como o único instrumento pedagógico.

Os educandos surdos possuem sua própria linguagem e cultura. É preciso que o professor compreenda pelo menos um pouco sobre esses pontos para justamente acontecer o estreitamento da relação professor-aluno, dando possibilidades para o profissional passar com mais fidedignidade o conteúdo e por fim alcançar os objetivos da aula. A lei que regulamenta o uso da Libras como linguagem materna para o público surdo entrou em vigor no ano de 2002, e os professores atualmente das escolas estão lecionando em média há 16 anos, período em que não era obrigatório essa disciplina na grade curricular dos mesmos.

Por esse motivo os professores que estão há mais tempo nas escolas não possuem conhecimento específico na área. Já os que têm menos tempo de magistério relatam que a disciplina de Libras não é suficiente para deixá-los seguros a atender escolares surdos, pois necessita complementar com algum curso de capacitação.

O bilinguismo como método para aperfeiçoar o aprendizado de educando surdo está sendo bastante aceito nas escolas do Brasil e pela comunidade surda. Com a capacitação dos professores através de cursos profissionalizantes na área oferecidas pelo governo nas escolas regulares, pode haver uma mudança no quadro dos profissionais participantes dessa pesquisa.

A melhor forma e a mais produtiva de estabelecer a comunicação com surdos é por meio da Libras, é preciso que os profissionais de educação física se sintam sensibilizados para o aprendizado da Língua para que haja melhoria na qualidade do ensino das escolas. Como sugestão palestras e treinamentos no período de planejamento ajuda na conscientização e preparação desses profissionais no ano letivo.

A realidade é que os graduandos estão saindo das faculdades e universidades mais preparados e sensíveis à realidade de atenderem esses alunos 
a qualquer momento, do que os professores com mais tempo de magistério em campo, pois a grade curricular ainda não estava adaptada à lei 10.436/2002.

Apesar de todos os estudos encontrados na literatura sobre o assunto, ainda se torna necessário à dedicação e realização de mais estudos voltados para identificar e solução dos problemas existentes relacionados a essa temática. 


\section{REFERÊNCIAS}

ALMEIDA, J. LIBRAS NA FORMAÇÃO DE PROFESSORES: percepções dos alunos e da professora. 2012. 146 f. Dissertação de (Mestrado) - Setor de Educação, da Universidade Estadual de Londrina, 2012. Disponível em < http://www.uel.br/pos/mestredu/images/stories/downloads/dissertacoes/2012/2012__ALMEIDA_Josiane_Junia_Facundo.pdf> Acesso em: 29 outubro 2016. p. 34 e 37.

ANACHE, A. A. RESENDE, D. A. R. Caracterização da avaliação da aprendizagem nas salas de recursos multifuncionais para alunos com deficiência intelectual. Revista Brasileira de Educação v. 21 n. 66 jul.-set. 2016. Campo Grande, MS.

BRASIL. Lei no 10436, de 24 de abril de 2002. Dispõe sobre a Língua Brasileira de Sinais-Libras e dá outras providências. Brasília, 24 de abril de 2002; 181ํ da Independência e 114ํ da República. Disponível em: <http://www6.senado.gov.br/legislacao/ListaPublicacoes.action?id=234606> Acesso em 27/03/2016 às 14:03.

Lei de Diretrizes e Bases da Educação Nacional. Brasília, Lei n. 9394, de 20 de

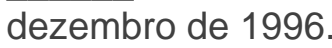

Secretaria de Educação Fundamental. Parâmetros curriculares nacional apresentação dos temas transversais, ética / Secretaria de Educação Fundamental. Brasília : MEC/SEF, 1997.

Decreto $\mathrm{n}^{0}$ 5.626, de 22 de dezembro de 2005. Diáro oficial [ da República Federativa do Brasil]. Brasília, DF. 22, de Dez. 2005. Seção 5.

IACHINSKI, L. T. et al. A inclusão da disciplina de Libras nos cursos de licenciatura: visão do futuro docente. Audiology - Communication Research, v. 24, p. 1-7, 2019.

JUNIOR, L. A. Z. ZANCANARO, T. M. L. A atuação dos intérpretes de Libras com educandos surdos no ensino fundamental. Revista Educação Especial | v. 29 | n. 54 | p. 83-94 | Santa Maria. Jan./abr. 2016.

PACHECO, J.; ALVES, M. L. T.; DUARTE, E. A formação inicial de professores de educação física acerca da inclusão: um estudo diagnóstico no Chile. Revista Brasileira de Educação Física e Esporte, v. 31, n. 3, p. 619-627, 2017.

PESSOAS com deficiência recebem até 1 salário mínimo. Deficiente o blog da inclusão de cidadania. Censo IBGE. Fortaleza 02 de jul. de 2012. Disponível em <http://www.deficienteciente.com.br/2012/07/censo-ibge-46-das-pessoas-com-deficienciarecebem-ate-1-salario.html> 27/03/2016 às 13:03

PIMENTA, W. A. et al. A inclusão de alunos surdos nas aulas de educação física no ensino regular na perspectiva da atuação do professor e da acessibilidade da escola. Revista Da Associação Brasileira De Atividade Motora Adaptada, v. 19, n. 2, p. 155-170, 2019.

MENDES, A. Q. S. FIGUEREDO, F. RIBEIRO, A. C. Inclusão de alunos surdos na escola regular: aspectos linguísticos e pedagógicos. Revista de Iniciação Científica - RIC Cairu. v. 02 n.2. Jun. 2015. 
NASCIMENTO Ribeiro L. C. SOFIATO Cássia G. A disciplina de língua brasileira de sinais no ensino superior e a formação de futuros educadores. Educação Temática Digital - ETD. Campinas, SP v.18 n.2 2016. P. 364.

NUNES S. S. et al. Surdez e educação: escolas inclusivas e/ou bilíngues? Psicologia Escolar e Educacional. vol.19 no.3 Maringá Junho de 2015

PORTILHO, Wanderson. PORTILHO, Ana. SOUZA, Adrielle. OLIVEIRA, Alexander. A formação docente do professor surdo: aproximações e distanciamentos com a identidade docente. Brazilian Journal of Health Review. Curitiba, v.4, n.2, p. 4120-4129 mar./apr. 2021

RODRIGUES, S. A. EDUCAÇÃO FÍSICA: o desafio da inclusão dos alunos Surdos. p. 13, 2017.

SANTOS, A. N. COELHO, O. A. M. B. S. KLEIN, M. Educação de surdos no Brasil e Portugal: políticas de reconhecimento linguístico, bilinguismo e formação docente. Scientific Electronic Library Online - SciELO. São Paulo. 11 de ago. 2016. Disponível em http://www.scielo.br/scielo.php?script=sci_arttext\&pid=S151797022016005005104\&lng=pt\&n rm=iso\&tlng=en Acesso em 05 de Dez. 2016.

SILVA, F. J. CZANOSKI, L. C. T. DANTAS, M. N. R. DAVID, M. C. A inclusão que exclui: a realidade dos alunos surdos da rede regular de ensino. Revista Eletrônica do Curso de Pedagogia das Faculdades OPET - Junho de 2016. Curitiba PR.

SILVA, R. M. PORTO, C. S. Análise da inclusão do aluno surdo nas aulas de Educação Física regular na perspectiva dos professores de uma Escola Estadual, na cidade de Caratinga, MG. Revista Digital. Buenos Aires - Año 20 - № 206 - Julio de 2015.

UCHÔA, J.; NICOLETTI, L.; CARDOSO, V. A inclusão do aluno com deficiência auditiva nas aulas de educação física: O Professor em Contexto. Revista Ciência e Conhecimento, v. 34, n. 12, p. 128-139, 2012. 


\section{APÊNDICES}

Apêndice 1 - Termo de consentimento livre e esclarecido.

TERMO DE CONSENTIMENTO LIVRE E ESCLARECIDO

$\mathrm{Eu}$,

participo por livre e espontânea vontade da

pesquisa intitulada "O conhecimento da Libras para os profissionais de educação física no atendimento de alunos surdos nas escolas estaduais de Fortaleza - CE". Sendo este, um projeto de Trabalho de Conclusão de Curso do aluno Antônio Wesley Barbosa Pereira, através do Curso de Graduação em Licenciatura em Educação Física da Faculdade Terra Nordeste - FATENE.

Ressalto ainda que esta pesquisa não oferece nenhum risco físico ou moral aos demais envolvidos.

Estou ciente que não receberei remuneração em troca da participação no projeto, a aplicação do questionário para os professores será realizada antes das aulas de Educação Física dos mesmos. Os dados serão coletados pelo pesquisador. Vale ressaltar que o nome do professor e os seus dados serão somente utilizados para os fins do conhecimento científico, mantendo-os no mais absoluto sigilo.

Para qualquer dúvida ou esclarecimentos sobre os procedimentos da pesquisa podem ser obtidas com o pesquisador pelo telefone (85) 98877-0828 e/ou e-mail: antoniowesleybarbosapereira@gmail.com

CONFIDENCIALIDADE DA PESQUISA: Os resultados da pesquisa serão divulgados sem a identidade dos participantes.

$\mathrm{Eu}$ declaro estar ciente e informado (a) sobre os procedimentos de realização da pesquisa, conforme explicitados acima, e aceito participar voluntariamente da mesma.

Agradeço antecipadamente sua atenção e colaboração.

Respeitosamente,

Antônio Wesley Barbosa

Pereira

Caso tenha entendido os procedimentos da pesquisa e aceite participar, por favor, assine abaixo. Uma via será mantida pelos pesquisadores a outra é sua. 
Apêndice 2 - Carta de anuência.

\section{CARTA DE ANUÊNCIA PARA AUTORIZAÇÃO DE PESQUISA}

IImo Sr. Dr. xxxxxxxxx

Solicitamos autorização institucional para realização da pesquisa intitulada "O conhecimento da Libras para os profissionais de educação física no atendimento de alunos surdos nas escolas estaduais de Fortaleza - CE". A ser realizada na Faculdade Terra Nordeste - FATENE, pelo aluno(a.) Antônio Wesley Barbosa Pereira, sob orientação do Prof.(a). Michele Gonçalves Torres, com o(s) seguinte(s) objetivo(s): verificar o conhecimento dos professores de educação física sobre o atendimento de educandos surdos nas escolas estaduais da cidade de Fortaleza CE. Ao mesmo tempo, pedimos autorização para que o nome desta instituição possa constar no relatório final bem como em futuras publicações na forma de artigo científico. Ressaltamos que os dados coletados serão mantidos em absoluto sigilo de acordo com a Resolução do Conselho Nacional de Saúde (CNS/MS) 466/12 que trata da Pesquisa envolvendo Seres Humanos. Salientamos ainda que tais dados sejam utilizados tão somente para realização deste estudo. Na certeza de contarmos com a colaboração e empenho desta Diretoria, agradecemos antecipadamente a atenção, ficando à disposição para quaisquer esclarecimentos que se fizerem necessária.

Fortaleza, de de 2021.

Prof(a). Michele Gonçalves Romcy Torres
( ) Concordamos com a solicitação
( ) Não concordamos com a solicitação

$\operatorname{Dr}(a) x x x x x x x x x x x x$

Diretoria da Instituição onde será realizada a pesquisa (CARIMBO) 
Apêndice 3 - Questionário

\section{QUESTIONÁRIO - PROFESSOR}

Sexo: ( ) M ( ) F

Idade: anos

Escola:

Região (da escola):

Tempo de magistério: anos

Nível máximo de formação:
( ) Graduação
( ) Doutorado
( ) Especialização
( ) Mestrado
( ) Pós-Doutorado

1. Possui formação para alunos com deficiência? ( ) Sim ( ) Não

Em caso afirmativo, especificar qual (nome / instituição / ano de início e conclusão):

2. Você possui ou já possuiu algum aluno (a) com surdez (com deficiência auditiva / surdos)? ( ) Sim ( ) Não

3. Caso sim, como você reagiu ao se deparar com o aluno com surdez em sua turma?

4. Você considera importante o professor saber Libras? ( ) Sim ( ) Não

5. Você teve disciplina de Libras na graduação? ( ) Sim ( ) Não

Em caso afirmativo, o conteúdo da disciplina Libras na graduação foi o suficiente para você atender pessoas com surdez na escola?

( ) Sim ( ) Não

6. Você sabe Libras?

( ) $\operatorname{Sim}$ ( ) Não

7. Você sente a necessidade de se capacitar nas áreas de educação física adaptada e inclusiva?

( ) $\operatorname{Sim}($ ) Não 
8. Sua carga horária de trabalho permite que você continue se capacitando profissionalmente?

( ) Sim ( ) Não

9. Se por acaso você tivesse ou tem alunos surdos na sua turma, que tipo de recursos alternativos você utilizaria para otimizar a compreensão deles nas suas aulas?

10. Em sua opinião, as políticas de inclusão estão sendo suficiente para a capacitação dos professores para o público de alunos com surdez? $\operatorname{Sim}($ ) Não

11. Qual sua maior dificuldade ao receber aluno com surdez nas suas aulas? (Caso já tenha alunos surdos, informe quais são suas dificuldades).

12. A avaliação da aprendizagem foi diferenciada para os alunos com surdez?

( ) Sim ( ) Não

Em caso afirmativo, como?

13. Você teve dificuldade para avaliar esse público diferenciado?

( ) $\operatorname{Sim} \quad$ ( ) Não

Em caso afirmativo, por quê?

14. Que dificuldades você encontra para a efetivação da inclusão do aluno com surdez na escola?

15. Você faria algum curso para facilitar a sua atuação com esse público específico?

( ) $\operatorname{Sim}$ ( ) Não 
16. Que sugestões você daria para que houvesse uma melhor inclusão dos alunos com surdez? 
Agência Brasileira ISBN

ISBN: 978-65-86230-79-6 